\title{
INFLUENCE OF EMBANKMENTS WITH PARAPETS ON THE CROSS-WIND TURBULENCE INTENSITY AT THE CONTACT WIRE OF RAILWAY OVERHEADS
}

\author{
Sergio Avila-Sanchez ${ }^{(1)}$, Oscar Lopez-Garcia ${ }^{(2)}$, Jose Meseguer ${ }^{(3)}$ \\ IDR/UPM, E.T.S.I. Aeronáuticos, Universidad Politécnica de Madrid \\ Plaza del Cardenal Cisneros, 3. E-28040 \\ Madrid, Madrid, Spain
}

Tel. +34913366353 Fax. +34913366363

E-mails: s.avila@upm.es ${ }^{(1)}$, oscar.lopez.garcia@upm.es ${ }^{(2)}$, j.meseguer@upm.es ${ }^{(3)}$

\begin{abstract}
Winds as an environmental factor can cause significant difficulties for the railway system operation. The railway overhead has been particularly vulnerable to cross-winds related problems, such as development of undamped oscillations due to galloping phenomenon. The installation of windbreaks to decrease the aerodynamic loads on the train can affect the loads on railway overheads triggering cable galloping. One essential parameter to indicate the influence of the parapet wake on the catenary contact wire is the turbulence intensity. In this paper the results of an experimental analysis of the turbulence intensity due to the presence of parapets carried out in a wind tunnel are reported. Embankments equipped with different parapets have been tested and turbulence intensity has been measured at both contact wire locations, windward and leeward. The relative influence of the parapets is measured through a reduced turbulence intensity, defined as the ratio between the turbulence intensity measured with parapet and the turbulence intensity in the case without any parapet on the embankment. In general the reduced turbulence intensity increases as the height of the parapet increases.
\end{abstract}

Keywords: catenary instabilities, wind tunnel tests, train aerodynamics

\section{INTRODUCTION}

Aerodynamic loads on train vehicles under cross-winds are of paramount importance in the lateral equilibrium of the vehicle. Centrifugal and gravitational forces interact together with aerodynamic lateral force and rolling moment affecting the lateral stability of train vehicles. In fact cross-wind can be responsible for overturning the vehicle if the cross-wind speed achieves a threshold value. Moreover, over the last decades train speeds have risen significantly, thereby increasing the overturning risk and leading to important concerns about the safe operation of trains

Aerodynamic loads on train vehicles under cross-wind are governed not only by the shape of the vehicles themselves but also by the shape of surrounding infrastructures. For example, on the top of embankments, cross-wind speed increases due to the presence of the embankment slope. Therefore, at exposed locations, such as bridges or embankments, cross-winds can cause significant difficulties to vehicle stability. The calculation of the cross-wind speed which is able to overturn the vehicle is of paramount importance in the safe operation of railway systems.

Accurate determination of the aerodynamic actions at such situations is one of the goals of current research $[1,2]$. The evaluation of aerodynamic loads has followed two approaches: experimental and numerical methods. Wind tunnel is the most common experimental technology used to determine aerodynamic loads on train vehicles, see for instance [1-7]. Numerical methods are nowadays a customary tool to determine aerodynamic loads on train vehicles under cross-wind, [8-10].

Windbreaks are one of the most common structures used to decrease the aerodynamic loads acting on a train due to cross-winds. From the morphological point of view, a simple windbreak can be made of solid or porous fences with or without eaves. The influence of different parapets on the 
aerodynamic loads acting on a train vehicle on a double-track bridge deck has been experimentally analyzed $[3,7]$. These studies show that aerodynamic loads can be drastically reduced provided that the parapet height is large enough and eaves are added to the windbreaks.

Embankments are the most usual construction to keep railway lines flat. These constructions consist of a plane which is built up over an artificial hill, commonly made of material obtained from a cutting. Other design and constructive requirements of embankments are long-term stability and adequate support of the railway lines. Baker [11] presented experimental results of the wind characteristics over railway embankments showing that the speed-up of the flow agreed quite well with the one proposed by ESDU [12] when the side slope of the embankment is about $27^{\circ}$. More recently, Lubitz and White [13] have also investigated the effect of the wind direction on the speed-up of the wind at sinusoidal hills. The influence of embankments on train loads under cross-winds has drawn the attention of researchers. For instance, using a wind tunnel, lateral and vertical aerodynamic force coefficients on a train over an embankment at different angles of attack have been measured in $[1,14]$

Another important concern for railway facilities is the aerodynamic loads that appear at the railway overhead and its influence on the dynamics of the interaction between railway overhead and vehicle pantograph. The railway overhead, also known as catenary, is the cable system responsible for providing the electrical supply to the train. The railway overhead is mainly made of three types of cables: contact wire, droppers and messenger wire. The contact wire transmits the electrical supply to the vehicle by mechanical contact with the train pantograph. As it is well know the railway cable systems can be quite vulnerable to cross-wind aerodynamic loads, as pointed out in $[15,16]$. More particularly, under cross-wind railway service has been cancelled and delayed at several locations of Scotland as it has been reported by Stickland and Scanlon [17].

Most of the problems related to cross-wind acting on railway structures are due to galloping phenomenon. This aerodynamic effect consists of the development of undamped oscillations of the cable structure when unsteady aerodynamic forces act on the structure itself. Because the contact wire cross section is a non-circular one, catenary wires can exhibit galloping phenomenon. When windbreaks are placed on the embankment, the boundary layer separates at its upper windward edge. The height of the separation point over the deck increases as the parapet height increases accordingly, and the vertical distance from the shear layer to the twin track increases. Therefore, the installation of parapets to protect train vehicles from lateral aerodynamic loads can trigger galloping phenomenon of the railway overhead. There exist a lack of literature to study the galloping phenomenon in railway overheads, and as far as the authors' knowledge is concerned only the application of simplified models based on the Glauert-Den Hartog criterion have been carried out, [16-18].

The aim of this article is the determination of the turbulence intensity at the catenary contact wire locations, both windward and leeward. The experimental evaluation of the turbulence intensity can be used as an input parameter to numerical models in order to study the complex dynamics of the interaction between catenary cable structure and crosswinds. Moreover, depending on the parapet height and its shape the use of windbreaks at embankments can lead to an increase of the turbulence intensity level at the catenary contact wire locations. Therefore, it is important to evaluate the geometry parameters and configuration details of the parapets to avoid the increment of turbulence intensity. In this paper several configurations of parapets at embankments have been experimentally studied and turbulence intensity have been measured using hot-wire anemometry at the catenary contact wire locations. Knowing the turbulence intensity levels it is expected that the design of future parapets located at embankments can be improved in order to increase the safety of the operation of railway systems under cross-winds.

\section{EXPERIMENTAL SET-UP}

\section{Equipment and Procedure}

A set of two-dimensional wind tunnel tests were carried out to characterize the influence of parapets on the flow turbulence intensity at both railway overhead locations. Test were performed in an open-circuit wind tunnel with a working section $1.8 \mathrm{~m}(5.91 \mathrm{ft})$ high, $0.2 \mathrm{~m}(0.66 \mathrm{ft})$ wide and $1.8 \mathrm{~m}$ $(5.91 \mathrm{ft})$ long.

A DANTEC hot-wire anemometer system (a probe type 55P16 connected to a CTA module 90C10) has been used to measure velocity magnitudes normal to the contact wire. Wind mean and root mean square (RMS) velocities were computed with the acquisition software StreamWare. The sampling rate and measuring period were $500 \mathrm{~Hz}$ and $20 \mathrm{~s}$, respectively, chose as appropriate after different preliminary tests. The hotwire was calibrated in a StreamLine $90 \mathrm{H} 02$ Flow Unit air jet calibrator. Temperature was also checked in order to ensure the validity of experimental results.

Figure 1 shows one sample of a complete mock-up made of embankment, twin track, and parapet together with hot-wire anemometer. The position shown corresponds to the configuration when no measurements are going to be performed. The hot-wire anemometer together with the parapet can turn around the rotation axis labeled in figure 1 as (A). To carry out the measurements the frame made of the hotwire anemometer and the parapet is turn around the axis (A) in such a way that the parapet wall labeled in figure as (B) ends up at the wind tunnel wall (C). In this way the complete mockup is configured as shown in Figs. 2.a and 2.b.

The hot-wire probe is placed at both windward and leeward catenary contact wire locations to measure the turbulence intensity in the orthogonal plane to the catenary.

As it is known, turbulence intensity is defined as

$$
I_{u}=\frac{\sigma_{u}}{U}
$$

where $U$ is the mean velocity obtained from the sampled data, and $\sigma_{u}$ stands for the velocity RMS value. 


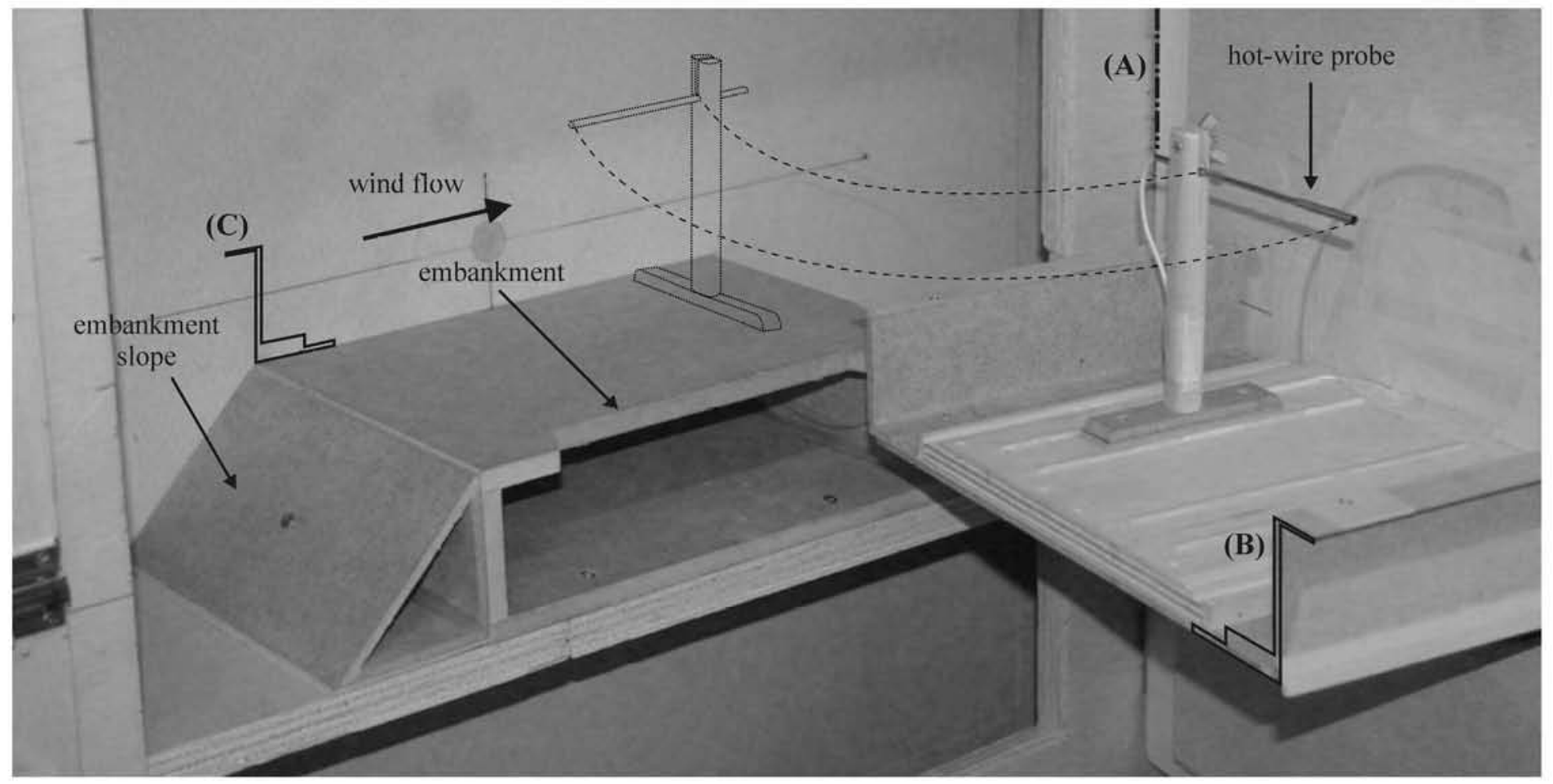

Figure 1 Photograph of the test chamber access. The hot-wire probe is positioned to measure turbulence intensity at the windward railway overhead location. The slope of the model shown is 1:1.

Experimental results presented in this paper are referred to the case of the twin track embankment without any wind protection. In order to establish a coefficient for the comparison of the different configurations, reduced turbulence intensity is defined as

$$
\eta=\frac{I_{u}}{I_{u 0}}
$$

where $I_{t 0}$ refers to the turbulence intensity measured without any parapet on the embankment.

\section{Test Model and Configurations}

Two models were built to reproduce embankments with different slopes and the twin railway track with the different windbreaks. Embankment slopes 1:1 and 1:2 were chosen as representative values of the railway infrastructure. As it is known, model dimensions in wind tunnel tests are limited to the geometric characteristics of the working section, but they should be able to reproduce the most important aerodynamic characteristics, both of the model and of the surroundings.

The scale of the twin track embankment was chosen 1/50th. The spanned ground as shown in Fig. 2.a was slightly larger than the embankment width $\left(\mathrm{c}+2 l_{S}\right)$ as represented in Fig. 2.b. This ensures a correct angle of incidence of the flow at the windward parapet model. Ground leading edge was rounded to prevent the boundary layer separation caused by sharp edges. It must be pointed out that the greater ratio of the model height to the working section was lower than 0.08 , so no blockage provisions were undertaken. As sketched in Fig. 2, the embankment slopes are triangular prisms $80 \mathrm{~mm}$ (3.15 in) height and wide enough to provide the required slope. Figure 2.b represents the twin track and embankment slope cross sections. As it is shown the parapet model is a solid wall $2.5 \mathrm{~mm}(0.1 \mathrm{in})$ thick placed perpendicular on both edges of the embankment. Seven different windbreak heights were analyzed: $h=5 \mathrm{~mm}, 10 \mathrm{~mm}, 15 \mathrm{~mm}, 25 \mathrm{~mm}, 35 \mathrm{~mm}, 45$ $\mathrm{mm}$ and $55 \mathrm{~mm}(h=0.20$ in, 0.39 in, 0.59 in, 0.98 in, 1.38 in, 1.77 in and 2.17 in).

All the parapets are equipped with different eaves, with the exception of the $5 \mathrm{~mm}(0.20 \mathrm{in})$ height windbreak, so twenty-five different types of parapets were tested. The four considered eave lengths were $a=5 \mathrm{~mm}, 10 \mathrm{~mm}, 15 \mathrm{~mm}$ and the parapet without eaves $a=0 \mathrm{~mm}$ ( $a=0.20 \mathrm{in}, 0.39 \mathrm{in}, 0.59$ in, and $0 \mathrm{in}$ ). 


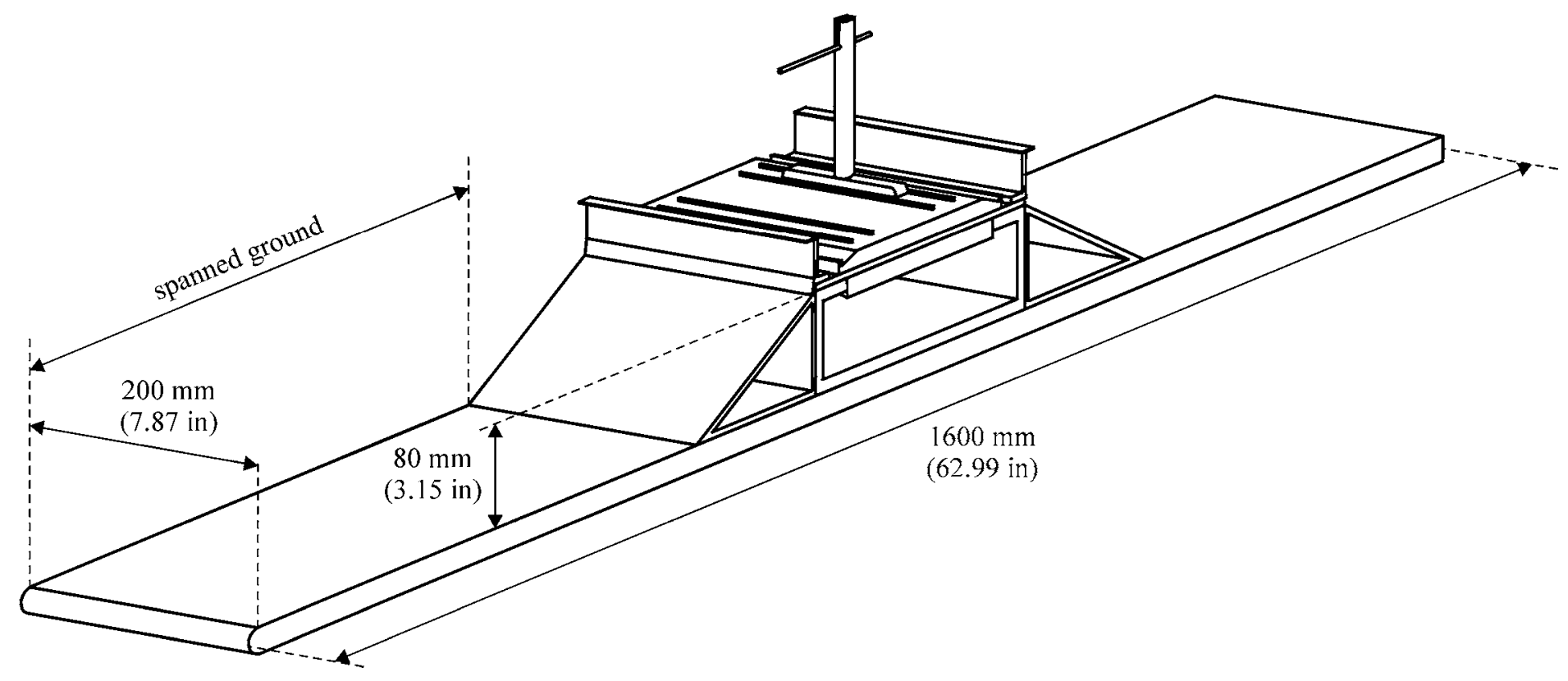

a. Sketch of the embankment model, with the twin railway track equipped with windbreaks. The hot-wire anemometer is positioned to measure the windward railway overhead.

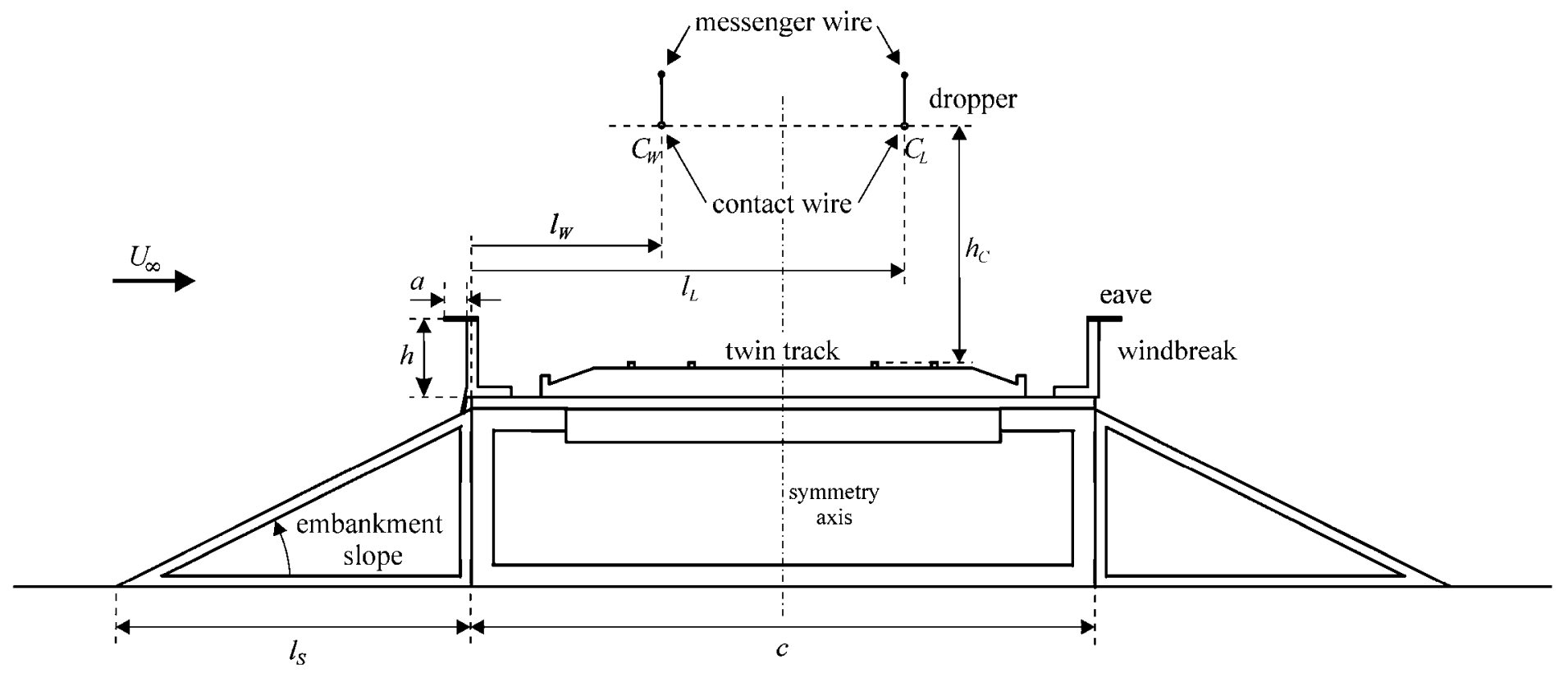

b. Sketch of the twin railway track equipped with windbreaks. The windbreak height, $h$, and the eave length, $a$, are defined in the windward parapet. The twin track length is $c=280 \mathrm{~mm}(11.02 \mathrm{in})$. The horizontal distance between windward and leeward catenary contact wires and the twin track windward edge are $I_{W}=85 \mathrm{~mm}(3.35 \mathrm{in})$ and $I_{L}=195 \mathrm{~mm}(7.68 \mathrm{in})$, respectively. The horizontal lengths of the embankment slope considered are $l_{S}=80 \mathrm{~mm}(3.15 \mathrm{in})$ for the $1: 1$ slope and $l_{S}=160 \mathrm{~mm}(6.30 \mathrm{in})$ for the $1: 2 \mathrm{slope}$.

Figure 2. Sketches of the embankment and twin railway track model. The embankment slope represented in both sketches is $1: 2$. 


\section{EXPERIMENTAL RESULTS}

In Fig. 3 is shown the reduced turbulence intensity measured at the windward catenary contact wire location of the embankment with slope 1:2. For each eave length, a polynomial of third order was fitted to the experimental results. As it has been widely studied embankment and hill slopes speed-up the flow [13, 19], but they also modifies the angle of incidence. As it has been previously mentioned, windbreaks decrease the magnitude of the velocity downstream. The size of the region which is affected by the speed reduction becomes bigger when the windbreak height increases. Considering all these effects, as the parapet height increases the wake caused by the windbreak on an embankment widens. Therefore the catenary contact wire could be located inside the parapet wake provided the windbreak is high enough. The increase in the reduced turbulence intensity is the direct consequence of this wake widening.

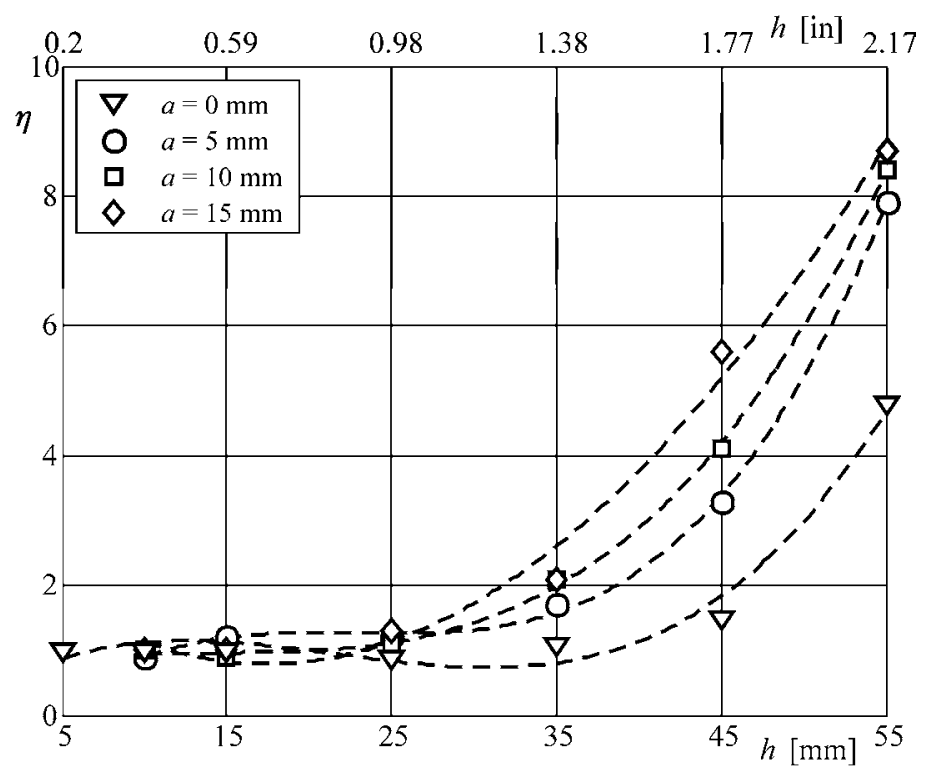

Figure 3. Reduced turbulence intensity, $\eta$, versus windbreak height, $h$, measured at the windward catenary location of the model with embankment slope 1:2. Four eave lengths, $a$, were considered: $0 \mathrm{~mm}$ (triangles), $5 \mathrm{~mm}$ (circles), $10 \mathrm{~mm}$ (squares) and $15 \mathrm{~mm}$ (diamonds). Dashed lines are the polynomial of third order fitted to the results.

Results at the leeward catenary contact wire location are presented in Fig. 4. The influence of windbreak height is more appreciable than in the windward contact wire. Lower parapet heights widen the wake downstream enough to place the leeward catenary contact wire inside the wake itself. Furthermore, the addition of the eave produces a qualitative change in the behavior of the reduced turbulence intensity at leeward contact wire. The reduced turbulence intensity shows a maximum for parapet height about $45 \mathrm{~mm}$ ( $1.77 \mathrm{in})$ and eave length less than $15 \mathrm{~mm}(0.59 \mathrm{in})$. Reduced turbulence intensity caused by large enough parapets with eaves is no longer greater than the corresponding to the parapet without eaves.

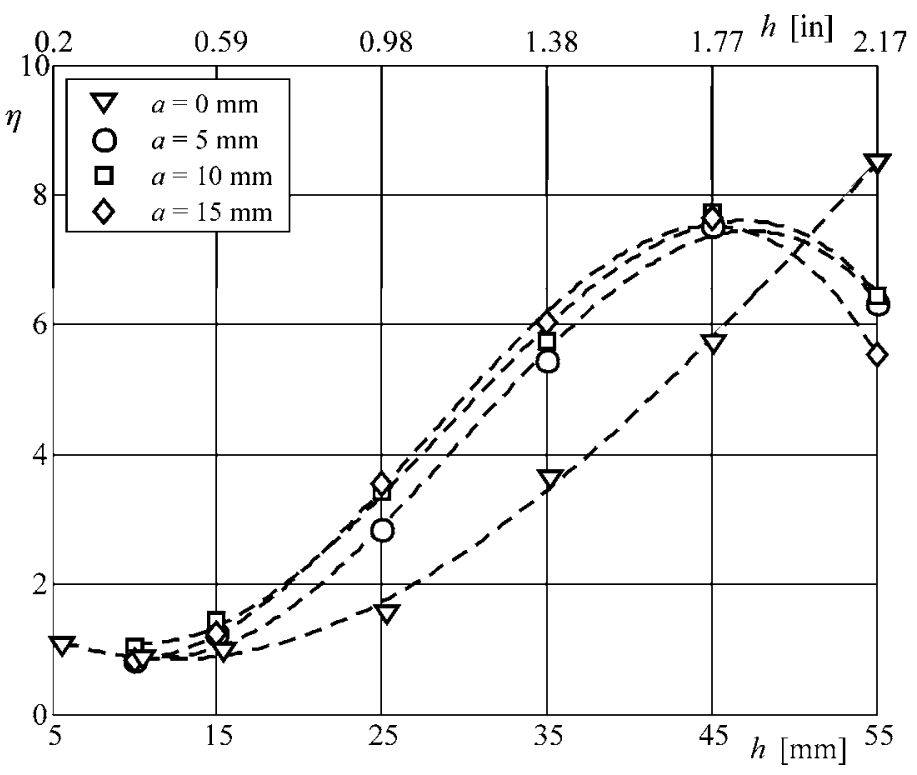

Figure 4. Reduced turbulence intensity, $\eta$, versus windbreak height, $h$, measured at the leeward catenary location of the model with embankment slope 1:2. Four eave lengths, $a$, were considered: $0 \mathrm{~mm}$ (triangles), $5 \mathrm{~mm}$ (circles), $10 \mathrm{~mm}$ (squares) and $15 \mathrm{~mm}$ (diamonds). Dashed lines are the polynomial of third order fitted to the results.

Reduced turbulence intensity at windward and leeward catenary contact wire locations is represented in Figs. 5 and 6, respectively, measured at the embankment with slope 1:1. The same qualitative behavior previously described is shown. Comparing results from both embankment slopes, reduced turbulence intensity in general shows a slightly increase. The incident angle of the flow near the windward windbreak increases as the slope of the embankment rises. As result the vertical distance from the shear layer produced by the parapet to the railway track increases.

Fitted equations for the leeward railway overheads at both embankments show more sensitivity to the installation of an eave than to an increment in its length. Dependency on the eave length of the reduced turbulence intensity is more appreciable at windward railway overhead, but provided a parapet large enough the same behavior could be expected. 


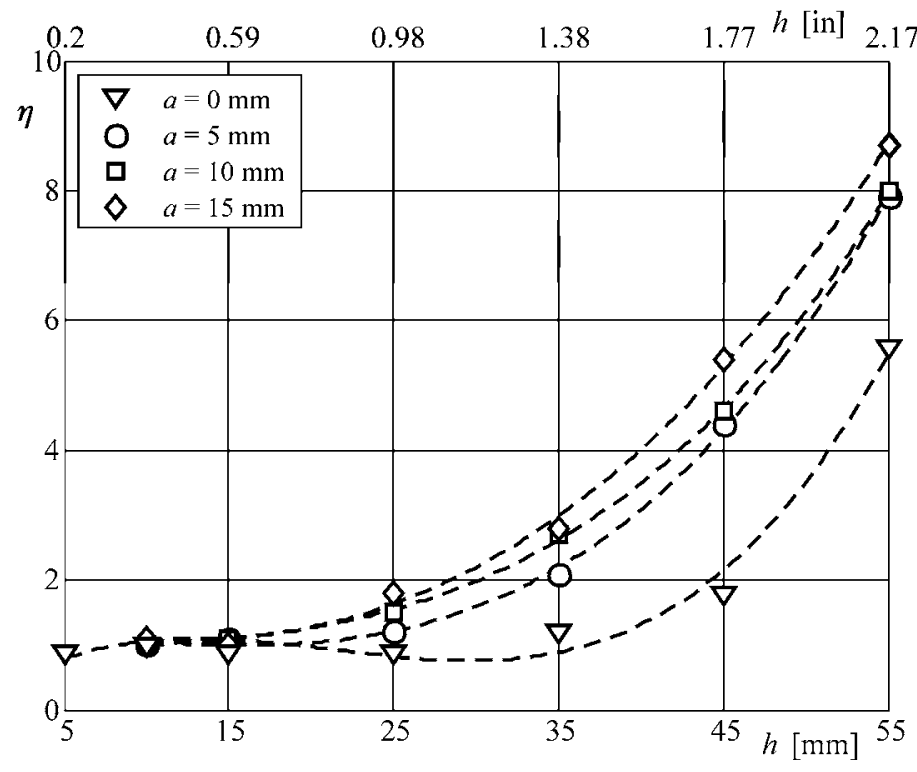

Figure 5. Reduced turbulence intensity, $\eta$, versus windbreak height, $h$, measured at the windward catenary location of the model with embankment slope 1:1. Four eave lengths, $a$, were considered: $0 \mathrm{~mm}$ (triangles), $5 \mathrm{~mm}$ (circles), $10 \mathrm{~mm}$ (squares) and $15 \mathrm{~mm}$ (diamonds). Dashed lines are the polynomial of third order fitted to the results.

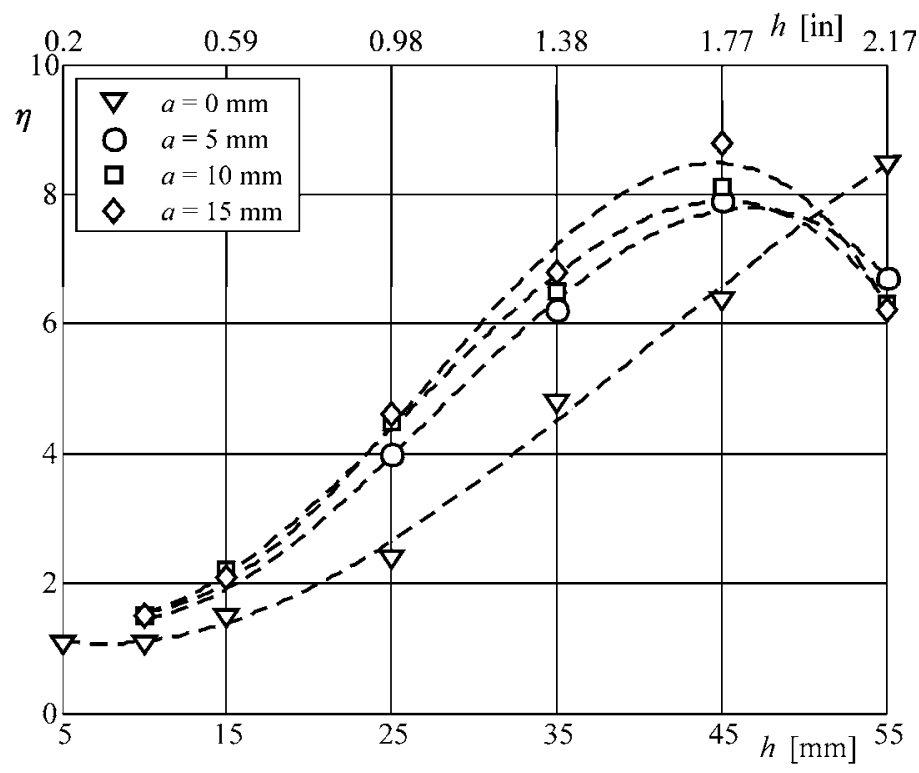

Figure 6. Reduced turbulence intensity, $\eta$, versus windbreak height, $h$, measured at the leeward catenary location of the model with embankment slope 1:1. Four eave lengths, $a$, were considered: $0 \mathrm{~mm}$ (triangles), $5 \mathrm{~mm}$ (circles), $10 \mathrm{~mm}$ (squares) and $15 \mathrm{~mm}$ (diamonds). Dashed lines are the polynomial of third order fitted to the results. summarizes the experimental results at the windward contact wire in both embankments. Using the polynomials of third order fitted to experimental results, three different values of the reduced turbulence intensity have been considered $(\eta=1$, $\eta=2$ and $\eta=5$ ). The values obtained for each eave length were used to interpolate constant reduced turbulence intensity curves. Two effects are appreciable, the first one is that the addition of the eave decreases the windbreak height required to keep undisturbed the reduced turbulence intensity. The second effect, as it has been previously mentioned, is that the greater the slope of the embankment, the greater the reduced turbulence intensity (provided the rest of parameters remain the same).

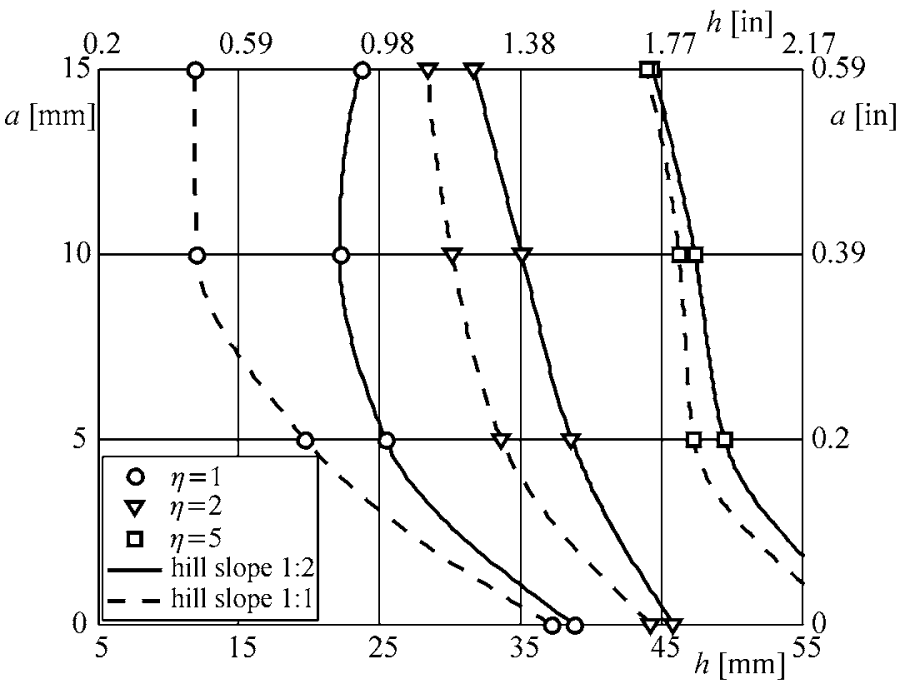

Figure 7 . Reduced turbulence intensity, $\eta$, at the windward catenary as function of windbreak height, $h$, and eave length, a. Solid lines correspond to the embankment slope 1:2, dashed lines to the embankment slope 1:1. Three different values of $\eta$ are considered, $\eta=1$ (circles), $\eta=2$ (triangles), $\eta=5$ (squares).

Reduced turbulence intensity its definition, Eq. (2), can not be less than 1 , so the curves $\eta=1$ are the upper bound of the region where the influence of the windbreak is negligible at the railway overhead location.

Figure 8 represents the dependency of reduced turbulence intensity on parapet height and eave length at leeward catenary contact wire, at both embankments. The results show the same trend as those measured at the windward catenary contact wire. However, parapet height has more influence on the flow quality degradation in the leeward catenary contact wire location than in the windward railway overhead.
In order to understand most of the mentioned trends, the dependency of the reduced turbulence intensity on the parapet height and eave length is represented in Figs. 7 and 8. Figure 7 


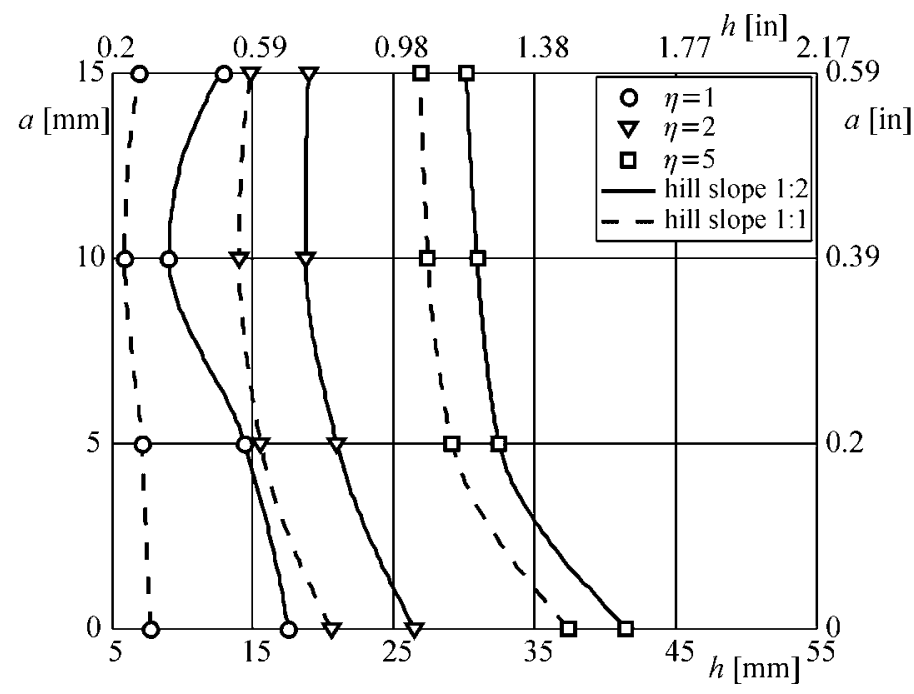

Figure 8. Reduced turbulence intensity, $\eta$, at the leeward catenary as function of windbreak height, $h$, and eave length, a. Solid lines correspond to the embankment slope 1:2, dashed lines to the embankment slope 1:1. Three different values of $\eta$ are considered, $\eta=1$ (circles), $\eta=2$ (triangles), $\eta=5$ (squares).

\section{CONCLUSIONS}

Windbreaks are simple solutions to reduce the rolling moments and lateral aerodynamic loads on train vehicles, induced by the cross-winds, which could jeopardize train stability. But parapets have a counterpart; they may deteriorate the downstream flow quality. Therefore special care should be taken designing windbreaks.

In this paper, reduced turbulence intensity has been chosen as a parameter to measure the degradation of the flow quality in embankments at both railway overheads location. Experimental results reveal that when the embankment is equipped with high enough windbreaks, turbulence intensity is increased compared to the reference case of embankment with no parapets. Results also show that the addition of eaves on the top of the parapet decreases the quality of the flow.

Figures. 7 and 8 summarize most of the relevant trends in the experimental results. The representation of reduced turbulence intensity level curves can be used as design guidelines, as they provide a simplified relationship between windbreaks geometry and flow quality degradation.

\section{ACKNOWLEDGEMENT}

This work has been supported by the Spanish Ministerio de Fomento, Centro de Estudios y Experimentación de Obras Públicas, CEDEX, under contract PT-2007-024-17CCPM and by Ministerio de Ciencia e Innovación, under contract TRA2009-13912-C012-01

\section{NOMENCLATURE}

a length of eaves

$c$ twin track width

$h$ parapet height

$h_{c}$ vertical distance between the catenary contact wires and the tracks

$I_{u}$ turbulence intensity at the catenary contact wire with a parapet on the embankment

$I_{u 0}$ turbulence intensity at the catenary contact wire without parapet on the embankment

$l_{l}$ horizontal distance between the leeward catenary contact wire and the twin track windward edge.

$l_{S}$ horizontal length of the embankment slope.

$l_{W}$ horizontal distance between the windward catenary contact wire and the twin track windward edge.

$U$ mean wind velocity at the catenary contact wire

$U_{\infty}$ wind velocity

$\eta$ reduced turbulence intensity, $\eta=I_{t t} / I_{t 0}$.

$\sigma_{u}$ root mean square value of the wind velocity at the catenary contact wire

\section{REFERENCES}

[1] Suzuki, M., Tanemoto, K., and Maeda, T., 2003, "Aerodynamic Characteristics of Train/Vehicles under Cross-Winds," Journal of Wind Engineering and Industrial Aerodynamics, 91, pp. 209-218.

[2] Sanquer, S., Barré, C., Dufresne de Virel, M., and Cléon, L.M., 2004, "Effect of Cross-Winds on High-Speed Trains: Development of a New Experimental Methodology," Journal of Wind Engineering and Industrial Aerodynamics, 92, pp. 535-545.

[3] Baker, C.J., 1986, "Train Aerodynamic Forces and Moments from Moving Model Experiments," Journal of Wind Engineering and Industrial Aerodynamics, 24, pp 227-251.

[4] Baker, C.J., and Humphreys, N.D., 1996, "Assessment on the Adequacy of Various Wind Tunnel Techniques to Obtain Aerodynamic Data for Ground Vehicles in CrossWinds," Journal of Wind Engineering and Industrial Aerodynamics, 60, pp. 49-68.

[5] Kwon, H., Park, Y., Lee, D., and Kim, M., 2001, "Wind Tunnel Experiments on Korean High-Speed Trains Using Various Ground Simulation Techniques," Journal of Wind Engineering and Industrial Aerodynamics, 89, pp. 1179-1195.

[6] Matschke, G., and Heine, C., 2002, "Full Scale Tests on Side Wind Effects on Trains. Evaluation of Aerodynamic Coefficients and Efficiency of Wind Breaking Devices," TRANSAERO: A European Initiative of Transient Aerodynamics for Railway System Optimisation, B. Schulte-Werning, R. Gregoire, A. Malfati and G. Matschke, eds., Springer, Berlin, pp. 27-38. 
[7] Barcala, M.A., and Meseguer, J., 2007, “An Experimental Study of the Influence of Parapets on the Aerodynamic Loads under Cross-Wind on a Two-Dimensional Model of Train Vehicle on a Bridge," Proc. Instn. Mech. Engrs., Part F. Journal of Rail and Rapid Transit, 221, pp. 487-494.

[8] Khier, W., Breuer, M., and Durst, F., 2000, "Flow Structure around Trains under Side Wind Conditions: a Numerical Study," Computers \& Fluids, 29, pp. 179-195.

[9] Bettle, J., Holloway, A.G.L., and Venart, J.E.S., 2003, "A Computational Study of the Aerodynamic Forces Acting on a Tractor-Trailer Vehicle on a Bridge on a CrossWind," Journal of Wind Engineering and Industrial Aerody namics, 91, pp. 573-592.

[10]Diedrichs B., 2003, "On Computational Fluid Dynamics Modelling Crosswind Effects for High-Speed Rolling Stocks," Proc. Instn. Mech. Engrs., Part F, Journal of Rail and Rapid Transit, 217, pp. 203-226.

[11]Baker, C.J., 1985, "The Determination of Topographical Exposure Factors for Railway Embankments," Journal of Wind Engineering and Industrial Aerodynamics, 21, pp. 89-99.

[12] Engineering Sciences Data Unit, 1990, "Strong Winds in the Atmospheric Boundary Layer Part 1: Mean-Hourly Wind Speeds," ESDU Publication 82026.

[13]Lubitz, W.D., and White, B.R., 2007, "Wind-Tunnel and Field Investigation of the Effect of Local Wind Direction on Speed-up over Hills," Journal of Wind Engineering and Industrial Aerodynamics, 95(8), pp. 639-661.

[14]Bocciolone, M., Cheli, F., Corradi, R., Muggiasca, S., and Tomasini, G., 2008, "Crosswind Action on Rail Vehicles: Wind Tunnel Experimental Analyses," Journal of Wind Engineering and Industrial Aerodynamics, 96 (5), pp. 584-610.

[15] Johnson, T., 1996, "Strong Wind Effects on Railway Operations - 16th October 1987," Journal of Wind Engineering and Industrial Aerodynamics, 60, pp. 251-266.

[16] Scanlon, T. J., Stickland, M., and Oldroyd, A., 2000, “An Investigation into the Attenuation of Wind Speed by the Use of Windbreaks in the Vicinity of Overhead Wires," Proc. Instn. Mech. Engrs., Part F, J. Rail and Rapid Transit, 214, pp. 173-182.

[17] Stickland, M., and Scanlon, T. J., 2001, "An Investigation into the Aerodynamic Characteristics of Catenary Contact Wires in a Cross-Wind," Proc. Instn. Mech. Engrs., Part F, J. Rail and Rapid Transit, 215, pp. 311-318.

[18] Stickland, M., Scanlon, T. J., Craighead, I. A., and Fernandez, J., 2003, "An Investigation into the Mechanical Damping Characteristics of Catenary Contact Wires and their Effect on Aerodynamic Galloping Instability," Proc. Instn. Mech. Engrs., Part F, J. Rail and Rapid Transit, 217, pp. 63-71.

[19] Carpenter, P., and Locke, N., 1999, "Investigation of Wind Speeds over Multiple Two-Dimensional Hills," Journal of Wind Engineering and Industrial Aerodynamics, 83, pp. $109-120$. 